\title{
Effect of the Pitch Size And Presence of Goalkeepers on the Work Load of Players During Small-Sided Soccer Games
}

\author{
by \\ Karel Hulka', Radim Weisser ${ }^{1}$, Jan Belka ${ }^{1}$
}

\begin{abstract}
Small-sided games (SSGs) are spontaneous forms of specific training where exercise intensity can be manipulated by modifying external factors. To ensure suitable usage of small-sided games in practice, we have to know which variables can influence internal responses and external loads. The aim of the present study was to determine the influence of presence of a goalkeeper and the pitch size on internal responses and the external load during five-a-side soccer games. Twenty nine junior soccer players (age: $18.11 \pm 1.31$ years; body mass index: $21.04 \pm 2.58 \mathrm{~kg} \cdot \mathrm{m}-2$; peak heart rate: $199.53 \pm 7.51$ beats.min-1) participated in the study. The heart rate, distance covered and the rate of perceived exertion were monitored. We found significantly higher average heart rates of players in 505 SSGs without goalkeepers than with them on a small pitch. Analysis showed significant differences in the time spent in $65-85 \%$ of the peak heart rate zone and $<65 \%$ of the peak heart rate zone on the small pitch. Furthermore, we found significantly higher distance covered by players during five-a-side games with goalkeepers than without them played on the small pitch. Our results indicate that the pitch size is a very important variable that influences the work load of players. The inclusion of the goalkeeper decreases the work load of the player on a small pitch (28 $\times 20 \mathrm{~m} ; 560 \mathrm{~m} 2)$, but not on a medium or large pitch.
\end{abstract}

Key words: heart rate, distance covered, specificity, RPE, tactical metabolic training.

\section{Introduction}

Soccer is a very popular team sport with nearly 200 million players worldwide (Dupont et al., 2002). It contains positive motivational and social factors that may facilitate compliance and persistence with sport and contribute to the maintenance of a physically active lifestyle (Krustrup et al., 2010).

Changes in team games aerobic conditioning concepts (Stone and Kilding, 2009) have led researchers to increase attention to specific means of players' development. According to Hoff et al. (2002) plain running is suitable for maximal oxygen uptake development, but not for the development of specific soccer aerobic capacity, which is much more dependent on aerobic peripheral than central adaptation (Buchheit and Laursen, 2013; Gamble, 2007). In high performance sports, it has been well documented that the maximum benefits are achieved when the training stimuli are similar to competitive demands (Bompa, 1983).

One of the most important training methods in soccer includes small-sided games (SSGs) (Clemente et al., 2012). SSGs are thought to be more suitable than traditional interval training for the development of particular physical characteristics required for matches as they involve the actual movement patterns used in soccer (Impellizzeri et al., 2006; Koklu et al., 2012). The popularity of SSGs stems from their high specificity (Little and Williams, 2006) and complexity (Reilly, 2005). SSGs are considered to be suitable to match specific aerobic conditioning (Hill-Haas et al., 2009; Impellizzeri et al., 2006;

1 - Department of Sport, Faculty of Physical Culture, Palacky University Olomouc, Czech Republic. 
Little, 2009; Little and Williams, 2006). Furthermore, a 6 week period of training sessions with SSGs increased the repeated sprint ability and enhanced changes of directions (Dellal et al., 2012). Moreover, SSGs combine conditioning together with the development of technical and tactical skills under the pressure of opponents (Hoff et al., 2002).

The work load of players during SSGs can be influenced by many variables such as dimensions of the pitch (Casamichana and Castellano, 2010), the number of players (Aslan, 2013; Castellano et al., 2013; Randers et al., 2014), rule modifications (Mallo and Navarro, 2007), continuous and intermittent modality (Impellizzeri et al., 2006) and goalkeepers' presence (Dellal et al., 2008; Mallo and Navarro, 2007) or coach encouragement (Rampinini et al., 2007).

So far the effects of participation of goalkeepers and the pitch size have been measured independently. We found no study that had dealt with a combination of these two variables. However, we presumed that an increased pitch size could decrease the influence of goalkeepers' presence on the work load. Higher distance between goals could result in lower responsibility of defenders in the SSGs without goalkeepers. In this study we aimed to determine the influence of presence of a goalkeeper and the pitch size on internal responses and the external load during five-a-side soccer games.

\section{Material and Methods}

\section{Participants}

Twenty nine junior soccer players (age: $18.11 \pm 1.31$ years; body mass index: $21.04 \pm 2.58$ $\mathrm{kg} \cdot \mathrm{m}^{-2}$; peak heart rate: $199.53 \pm 7.51$ beats $\cdot \mathrm{min}^{-1}$ ) participated in the study. All procedures were conducted after the competitive part of the season (June and July, 2014). Participation was voluntary and players could withdraw from the study at any time. The aims and objectives of the present study were clarified with all participants and all of them provided written informed consent. The project was approved by the local ethics committee of the Faculty of Physical Culture Palacký University Olomouc (Czech Republic).

\section{Measures}

All participants completed peak heart rate
(HR peak $)$ measurement by the Yo-Yo intermittent level 2 (YYIRT1) test (Bangsbo et al., 2008), established for each player individually. Aslan et al. (2012) found a strong relationship between measured HReak by the YYIRT1 and a laboratory test of running on a treadmill. The measurement was made during training after one day off (Tuesday) and one week before the first measured practice.

All participants were evaluated during six practice sessions which included SSGs. The practices took place on a standard sized soccer pitch with an artificial grass surface. Every practice the players played one type of SSGs (with or without a goalkeeper on a small, medium or large pitch) always in the first part of the practice after a warm up.

To determine the distance covered (an indicator of the external load), footages of SSGs were analysed by a standardised procedure using the software package Video Manual Motion Tracker 1.0 (Hulka et al., 2014). The heart rate was monitored during all measurements by the TEAM Polar2Pro system (Polar Electro, Kempele, Finland) and the results were expressed as a percentage of the HRpeak of each participant. The heart rate zones were determined according to Barbero-Alvarez et al. (2008) as high intensity work ( $>85 \%$ of the $\mathrm{HR}_{\text {peak }}$ ), medium intensity work $(85-65 \%$ of the HRpeak) and low intensity work ( $<65 \%$ of the HReaa).

A global rate of perceived exertion was recorded just after the five-a-side games using the Borg scale CR-10 (RPE, Category rate scale 1-10) to evaluate the subjective psycho-physiological strain of the players (Castagna et al., 2011). The participants were instructed and familiarised with the scale at the end of two sessions before starting the measurement sessions.

\section{5-a-side soccer game (5v5 SSG)}

The participants wore blue T-shirts with large orange numbers (corresponding with official soccer rules) to permit clear identification. The size of the pitch and goalkeeper's presence were the dependent variables. The 5v5 SSG was played on the small $\left(28 \times 20 \mathrm{~m} ; 560 \mathrm{~m}^{2}\right)$, medium $(25 \times 35$ $\left.\mathrm{m} ; 875 \mathrm{~m}^{2}\right)$ and large $\left(42 \times 30 \mathrm{~m} ; 1260 \mathrm{~m}^{2}\right)$ pitches according to Rampinini et al. (2007) and was played to standard goals $(3 \times 2 \mathrm{~m})$ according to standard soccer rules. The 5v5 SSG was played five versus five players without goalkeepers and 
five versus five players with goalkeepers. The number and duration of the work interval and active recovery was determined according to Rampinini et al. (2007) as three times $4 \mathrm{~min}$. To avoid excessively long game stoppages, the balls were disposed around the game areas for immediate availability.

\section{Statistical analysis}

Statistical analysis was performed using the data analysis software system Statistica (10.0 version, StatSoft, Inc., Tulsa, USA). The prerequisites of normality and homogeneity of variance were verified using the KolmogorovSmirnov and Lilliefors tests, respectively. Data were expressed as means $(x) \pm$ standard deviation $(S D)$. One-way ANOVA was used to determine the significance of differences between measurement sessions $(p \leq 0.05)$. The effect size was calculated as $\omega^{2}=[F \cdot(k-1)]-k+1 /[F \cdot(k-1)]+\underline{n}-k+1$, where $k$ is the number of groups, $n$ is the number of participants, and $F$ is ANOVA value. Statistical significance of the differences between the results of particular measurements was verified by the post-hoc Tukey's HSD test. The level of significance was determined at an alpha level of $p<0.05$.

\section{Results}

The percentages of average heart rates of players were $84.75 \pm 1.01 \% \quad(169.33 \pm 6.24$ beats $\left.\cdot \mathrm{min}^{-1}\right)$ on the small, $87.15 \pm 1.17 \%(173.43 \pm$ 8.47 beats $\left.\mathrm{min}^{-1}\right)$ on the medium, and $88.62 \pm$ $1.07 \%\left(176.36 \pm 7.51\right.$ beats $\left.\cdot \mathrm{min}^{-1}\right)$ on the large pitch during 5v5 SSGs with the goalkeepers. During $5 \mathrm{v} 5$ SSGs without the goalkeeper, the players achieved $87.38 \pm 1.18 \%$ of the HReak $(174.25 \pm 6.47$ beats $\left.\mathrm{min}^{-1}\right)$ on the small, $91.73 \pm 1.07 \%$ of the $\mathrm{HR}_{\text {peak }}\left(172.56 \pm 7.47\right.$ beats $\left.\cdot \mathrm{min}^{-1}\right)$ on the medium, and $89.48 \pm 1.16 \%$ of the $\mathrm{HR}_{\text {peak }}(177.08 \pm 5.83$ beats. $\mathrm{min}^{-1}$ ) on the large pitch. Average distance covered on the small pitch was $372.41 \pm 13.81 \mathrm{~m}$ with the goalkeepers and $355.64 \pm 17.01 \mathrm{~m}$ without them, on the medium pitch $373.41 \pm 21.05 \mathrm{~m}$ with the goalkeepers and $367.08 \pm 17.13$ without them, and on the large pitch the values were equal to $496.81 \pm 26.11 \mathrm{~m}$ and $488.73 \pm 26.68 \mathrm{~m}$, respectively.

\begin{tabular}{|c|c|c|c|c|c|c|}
\hline & & & & \multicolumn{3}{|c|}{ Table 1} \\
\hline \multicolumn{7}{|c|}{ Values of mean percentages of the HR peak during $5 v 5$ SSGs } \\
\hline & Swith & Swithout & $\mathbf{M}_{\text {with }}$ & Mwithout & Lwith & Lwithout \\
\hline$>85 \%$ & $60.75 \pm 10.50$ & $63.15 \pm 11.25$ & $65.15 \pm 13.65$ & $64.85 \pm 15.54$ & $66.25 \pm 14.14$ & $64.48 \pm 12.89$ \\
\hline $65-85 \%$ & $26.01 \pm 5.33^{*}$ & $34.15 \pm 6.15^{*}$ & $24.58 \pm 7.52$ & $27.26 \pm 11.21$ & $27.85 \pm 6.36$ & $27.68 \pm 7.18$ \\
\hline$<65 \%$ & $11.25 \pm 2.89^{*}$ & $4.85 \pm 2.02^{*}$ & $10.12 \pm 3.01$ & $8.11 \pm 2.81$ & $5.58 \pm 0.92$ & $7.52 \pm 1.26$ \\
\hline RPE & $4.91 \pm 1.26$ & $4.65 \pm 1.09$ & $5.05 \pm 1.99$ & $5.72 \pm 1.36$ & $7.50 \pm 1.75$ & $7.13 \pm 1.12$ \\
\hline \multicolumn{7}{|c|}{$\begin{array}{l}\text { The values are means } \pm \text { SD; } \text { sith }-5 v 5 \text { SSGs on the small pitch with a goalkeeper; } \\
\text { Swithout - 5v5 SSGs on the small pitch without a goalkeeper; } \\
\text { Mwith - 5v5 SSGs on the medium pitch with a goalkeeper; } \\
\text { Mwithout - 5v5 SSGs on the medium pitch without a goalkeeper; } \\
\text { Lwith - 5v5 SSGs on the large pitch with a goalkeeper; } \\
\text { Lwithout - } 5 v 5 \text { SSGs on the large pitch without a goalkeeper; } \\
>85 \% \text { - percentage of time spent in the }>85 \% \text { heart rate zone; } \\
65-85 \% \text { - percentage of time spent in the } 65-85 \% \text { heart rate zone; } \\
<65 \% \text { - percentage of time spent in the }<65 \% \text { heart rate zone; } \\
\text { RPE - rate of perceived exertion; }{ }^{*} \text { - statistically significant differences. }\end{array}$} \\
\hline
\end{tabular}


We found significantly higher average heart rates in players in 5v5 SSGs without the goalkeepers than with them on the small pitch $\left(F=4.63 ; p=.01 ; \omega^{2}=0.22\right)$. However, we did not observe any significant differences of average heart rates on the medium $\left(F=0.09 ; p=.76 ; \omega^{2}=0.03\right)$ and large pitch $\left(F=0.33 ; p=.68 ; \omega^{2}=0.04\right)$ in $5 \mathrm{v} 5$ SSGs played with and without the goalkeepers. The average time spent in individual heart rate zones is presented in Table 1. Further statistical analysis showed significant differences in the time spent in the $65-85 \%$ of the HReak zone $(F=3.22$; $\left.p=.04 ; \omega^{2}=0.17\right)$ and the $<65 \%$ of the HRpeak zone $\left(F=3.96 ; \quad p=.02 ; \quad \omega^{2}=0.17\right)$ with and without goalkeepers on the small pitch.

We also found significantly higher distance covered by players during $5 \mathrm{v} 5$ SSGs with goalkeepers than without them played on the small pitch ( $\left.\mathrm{F}=5.29 ; \mathrm{p}=.03 ; \omega^{2}=0.15\right)$, but not on the medium ( $\left.\mathrm{F}=0.49 ; \mathrm{p}=.50 ; \omega^{2}=0.02\right)$ and large pitch $\left(\mathrm{F}=0.42 ; \mathrm{p}=.52 ; \omega^{2}=0.02\right)$.

Significant differences were also registered in average heart rates of players on different size of the pitch in the 5v5 SSGs with goalkeepers $\left(F=6.29 ; p=.02 ; \omega^{2}=0.17\right)$ and without them $(F=7.01$; $\left.p=.02 ; \omega^{2}=0.24\right)$. Further analysis showed that the internal response was significantly higher during $5 \mathrm{v} 5$ SSGs on the large pitch than on the small (HSD; $p=.03$ with goalkeepers and $p=.04$ without them) and medium (HSD; $p=.02$ with goalkeepers and $p=.03$ without them) ones. No significant differences were observed in the time spent in individual heart rate zones. However, we found significantly higher distance covered $(F=4.14$; $p=.02 ; \omega^{2}=0.15$ ) by players on the large pitch than on the other ones (HSD; $p=.01$ with goalkeepers and $p=.01$ without them). Finally, no significant differences in the values of the RPE at the end of $5 \mathrm{v} 5$ SSGs with or without goalkeepers were noted, but we found increasing RPE values with increasing pitch size.

\section{Discussion}

Small-sided games are a suitable means to develop soccer-specific aerobic conditioning despite any disadvantages such as exact control of work intensity (Krustrup et al., 2010; Little, 2009). The research on variables that can influence the reliability and exercise intensity is very important to prevent undertraining or overtraining (Dellal et al., 2011; Hill-Haas et al., 2011). Casamichana and
Castellano (2010) evaluated the effect of the pitch size on the work load and Dellal et al. (2008), as well as Mallo and Navarro (2007) investigated the effect of presence of a goalkeeper on the work load. However, no previous study had analyzed the combination of these two variables. Higher distance between goals could result in lower responsibility of defenders in the SSGs without goalkeepers. In this study we attempted to determine the influence of presence of a goalkeeper and the pitch size on internal responses and the external load during five-a-side soccer games.

All measured average heart rates were close to and over $85 \%$ of the HRpeak. Such values are considered to be a significant stimulus to the cardiovascular system (Hoff et al., 2002), thus, all measured SSGs could be used as aerobic capacity development drills. The results of the study of Casamichana and Castellano (2010) showed very similar values of the external load and internal response and presented the same increased tendency in all variables with an increasing pitch size. However, Aslan (2013) analyzed a five-a-side game on a pitch size of $1012 \mathrm{~m} 2$, which was the area between our medium and large pitch sizes. Nevertheless, he showed a much lower work load of players compared to other studies. This could be probably caused by lower performance levels of evaluated players, as technical and tactical awareness could limit performance of the players during small-sided games (Dellal et al., 2011). Casamichana and Castellano (2010) found that effective playing time could provide a potential explanation for the differences in physiological and physical demands. As the individual playing area was reduced, the frequency of motor behaviour increased, with a concomitant decrease in effective playing time (since a greater number of rule-related interruptions leads to a shorter effective playing time). At the same time, the players covered less distance, spending more time standing or walking, which led to a lower physiological work load and lower ratings of perceived exertion (Aguiar et al., 2012).

The presence or absence of a goalkeeper in the SSGs has some effect on players' physiological and technical responses (Aguiar et al., 2012). Mallo and Navarro (2007) suggested that the inclusion of a goalkeeper modified the physiological and tactical behaviour of the 
players. The authors found lower heart rates in the SSGs with goalkeepers than in the SSGs without them. Furthermore, they observed a predominance of medium-intensity activities in the SSGs with goalkeepers, which could cause the difference in average heart rates. These results were not confirmed by Dellal et al. (2008), who found an increase of $10.7 \%$ in the average heart rate in the 8-a-side soccer game with goalkeepers. However, the authors found a lower game intensity when the goalkeepers were present. Therefore, according to Hill-Haas et al. (2011) the influence of goalkeepers on exercise intensity in small-sided soccer games is not clear.

Our results showed that the reason for these discrepancies could be caused by other variables influencing the work load. In our study differences were found only when the SSGs were played on a small pitch. We assume that enlarging the pitch decreases players' awareness due to a longer distance to goal. When playing without goalkeepers, the players will probably be organised more defensively in order to protect their goal, what also influences game intensity. The study of different variables' effects could be deepened and researchers should look for other variables or combinations of variables that can have impact on the work load of the players.

Deeper statistical analysis showed significant differences in the time spent in the 65$85 \%$ of the HRpeak zone and the $<65 \%$ of the HRpeak zone on the small pitch. These results showed that goalkeeper absence on the small pitch shortened the recovery time represented by time spent in the $<65 \%$ of the HRpeak zone at the expense of the medium intensity heart rate zone. The reason for these discrepancies is the increased positional play of defenders. Consequently, the players had to cover defensive positions and also defend much closer to their opponents, hence the players reached a higher external load and internal response.

The total pitch area, both in absolute and relative terms, can be varied, and this may influence the intensity of SSGs. The majority of studies (Aslan, 2013; Castellano et al., 2013; Rampinini et al., 2007) report an increased heart rate, rate of perceived exertion and blood lactate concentration response with an increased pitch area (Hill-Haas et al., 2011). Our results indicate that the pitch size is a very important variable that influences the heart rate and distance covered by players during SSGs. We obtained very similar results to other studies dealing with the pitch size. However, a relatively small sample size of the present study can limit the results.

\section{Conclusion}

The size of the pitch during five-a-side soccer game influenced the external load and internal response of the players, when played with goalkeepers and without them. Inclusion of a goalkeeper decreases the work load of players on the small pitch $(28 \times 20 \mathrm{~m} ; 560 \mathrm{~m} 2)$, but not on the medium ( $25 \times 35 \mathrm{~m} ; 875 \mathrm{~m} 2)$ and large (42 x $30 \mathrm{~m}$; $1260 \mathrm{~m} 2$ ) pitches. The differences in the work load on the small pitch were caused by decreased the time spent in the low intensity heart rate zone at the expense of the medium intensity heart rate zone. The contradictory results about the effect of goalkeepers' inclusion suggest that future studies in this area should investigate in more depth the variables influencing the work load and technical performance of the players during different types of small-sided games.

\section{Acknowledgements}

The research was performed within support of a grant "New technologies and approaches to physical activity monitoring: Utilization in kinantropology research" (IGA_FTK_2015_003).

\section{References}

Aslan A. Cardiovascular Responses, Perceived Exertion and Technical Actions During Small-Sided Recreational Soccer: Effects of Pitch Size and Number of Players. J Hum Kinet, 2013; 38: 95-105

Aslan E, Muniroglu S, Alemdaroglu U, Karakoc B. Investigation of performance responses of Yo-Yo and shuttle run tests with thew treadmill run test in young soccer players. Pam J Sport Sci, 2012; 3(3): 104112

Aguiar M, Botelho G, Lago C, Macas V, Sampaio J. A Review on the Effects of Soccer Small-Sided Games. J Human Kinet, 2012; 33: 103-113 
Bangsbo J, Iaia M, Krustrup P. The Yo-Yo intermittent recovery test. A useful tool for evaluation of physical performance in intermittent sports. Int J Sport Med, 2008; 38: 37-51

Barbero-Alvarez JC, Soto VM, Barbero-Alvarez V, Granda-Vera J. Match analysis and heart rate of futsal players during competition. J Sports Sci, 2008; 26(1): 63-73

Buchheit M, Laursen PB. High-Intensity Interval Training, Solutions to the Programming Puzzle. Sports Med, 2013; 43(10): 927-954

Casamichana D, Castellano J. Time-motion, heart rate, perceptual and motor behaviour demands in smallsides soccer games: Effects of pitch size. J Sports Sci, 2010; 28(14): 1615-1623

Castagna C, Impellizzeri FM, Chaouachi A, Ben Abdelkrim N, Manzi V. Physiological responses to balldrills in regional level male basketball players. J Sports Sci, 2011; 29(12): 1329-1336

Castellano J, Casamichana D, Dellal A. Influence of Game Format and Number of Players on Heart Rate Responses and Physical Demands in Small-Sided Soccer Games. J Strength Cond Res, 2013; 27(5): 12951303

Clemente F, Couceiro MS, Martins ML. The usefulness of small-sided games on soccer training J Phys Ed Sport, 2012; 12(1): 93-102

Dellal A, Hill-Haas S, Lago-Penas C, Chamari K. Small-Sided Games in Soccer: Amateur Vs. Professional Players' Physiological Responses, Physical, and Technical Activities. J Strength Cond Res, 2011; 25(9): 2371-2381

Dellal A, Chamari K, Pintus A, Girard O, Cotte T, Keller D. Heart Rate Responses during Small-Sided Games and Short Intermittent Running Training in Elite Soccer Players: A Comparative Study. J Strength Cond Res, 2008; 22(5): 1449-1457

Dellal A, Varliette C, Owen A, Chirico, EN, Pialoux, V. Small-Sided Games Versus Interval Training in Amateur Soccer Players: Effects on the Aerobic Capacity and the Ability to Perform Intermittent Exercises with Changes of Direction. J Strength Cond Res, 2012; 26(10): 2712-2720

Dupont G, Blondel N, Lensel G, Berthoin S. Critical velocity and time spent at a high level of $\mathrm{VO}_{2}$ for short intermittent runs at supramaximal velocities. Canadian J Appl Physiol, 2002; 27(2): 103-115

Gamble P. Challenges and game-related solutions to metabolic conditioning for team sports. Strength Cond J, 2007; 29(4): 60-65

Hill-Haas SV, Dawson B, Impellizzeri FM, Coutts AJ. Physiology of small-sided games training in football: a systematic review. Sports Med, 2011; 41(3): 199-220

Hill-Haas SV, Rowsell GJ, Dawson BT, Coutts AJ. Acute Physiological Responses and Time-Motion Characteristics of Two Small-Sided Training Regimes in Youth Soccer Players. J Strength Cond Res, 2009; 23(1): 111-115

Hoff J, Wisloff U, Engen LC, Kemi OJ, Helgerud J. Soccer specific aerobic endurance training. Brit J Sport Med, 2002; 36(3): 218-221

Hulka K, Cuberek R, Svoboda Z. Time-motion analysis of basketball players: a reliability assessment of Video Manual Motion Tracker 1.0 software. J Sports Sci, 2014; 32(1): 53-59

Impellizzeri FM, Marcora SM, Castagna C, Reilly T, Sassi A, Iaia FM, Rampinini E. Physiological and performance effects of generic versus specific aerobic training in soccer players. Int J Sports Med, 2006; 27(6): 483-492

Impellizzeri FM, Marcora SM, Castagna C, Reilly T, Sassi A, Iaia M, Rampinini E. Physiological and performance effects of generic versus specific aerobic training in soccer players. Int J Sport Med, 2006; 27: 483-492

Koklu Y, Ersoz G, Alemdaroglu U, Asc A, Ozkan A. Physiological responses and time-motion characteristics of 4-a-side small-sided game in young soccer players: the influence of different team formation 
methods. J Strength Cond Res, 2012; 26(11): 3118-3123

Krustrup P, Dvorak J, Junge A, Bangsbo J. Executive summary: the health and fitness benefits of regular participation in small-sided football games. Scand J Med Sci Sports, 2010; 20(1): 132-135

Little T. Optimizing the Use of Soccer Drills for Physiological Development. Strength Cond J, 2009; 31(3): 6774

Little T, Williams AG. Suitability of soccer training drills for endurance training. J Strength Cond Res, 2006; 20(2): 316-319

Mallo J, Navarro E. Physical load imposed on soccer players during small-sided training games. J Sport Med Phys Fit, 2007; 48(2): 166-171

Rampinini E, Impellizzeri FM, Castagna C, Abt G, Chamari K, Sassi A, Marcora SM. Factors influencing physiological responses to small-sided soccer games. J Sports Sci, 2007; 25(6): 659-666

Randers MB, Nielsen JJ, Bangsbo J, Krustrup P. Physiological response and activity profile in recreational small-sided football: No effect of the number of players. Scand J Med Sci Sports, 2014; 24: 130-137

Reilly T. An ergonomics model of the soccer training process. J Sports Sci, 2005; 23(6): 561-572

Stone NM, Kilding AE. Aerobic Conditioning for Team Sport Athletes. Sports Med, 2009; 39(8): 615-642

\section{Corresponding author:}

\section{Karel Hulka}

Department of Sport, Faculty of Physical Culture, Palacky University Olomouc, Czech Republic Hynaisova 9 77900 Olomouc

Czech Republic

Phone: +420777320009

E-mail: karel.hulka@upol.cz 